\title{
DETERMINANTS OF RETURN TO PLAY AFTER ANTERIOR CRUCIATE LIGAMENT RECONSTRUCTION
}

\section{DETERMINANTES DO RETORNO AO ESPORTE APÓS RECONSTRUÇÃO DO LIGAMENTO CRUZADO ANTERIOR}

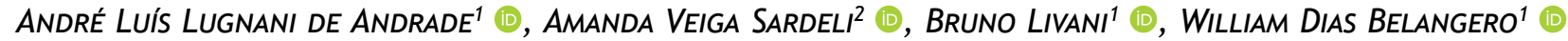 \\ 1. Universidade Estadual de Campinas, School of Medical Sciences, Campinas, SP, Brazil. \\ 2. Universidade Estadual de Campinas, School of Physical Education, Exercise Physiology Laboratory, Campinas, SP, Brazil.
}

\section{ABSTRACT}

Objective: To systematically review and meta-analyze the performance of return to play (RTP) and non-RTP patients in different assessment tools after anterior cruciate ligament reconstructions (ACLR). Methods: Out of 182 studies searched on PubMed, 11 presented RTP and non-RTP groups assessing the performance of young individuals, practitioners of different sports, with different tools. Results: There was higher limb symmetry $(7.13 \%[95 \% \mathrm{Cl} 4.55 ; 9.70], p<0.001)$, Tegner activity scale $(2.41[95 \% \mathrm{Cl} 0.18 ; 4.64], p=0.03)$, functional scores such as International Knee Documentation Committee (x7.44 [95\%Cl 4.69; 10.19], $p<0.001)$, Knee Osteoarthritis Outcome score for quality of life $(14.75$ [95\%Cl 10.96; 18.54], $p<0.001)$ and for sports/ recreation (11.86 [95\%Cl 8.87; 14.86], $p<0.001)$; and lower knee laxity $(-0.25 \mathrm{~mm}[95 \% \mathrm{Cl}-0.36$; -0.14$], p<0.001)$ in RTP compared to non-RTP patients following ACLR. Conclusion: We confirmed that these different tools can differentiate RTP for non-RTP patients, which may contribute to the physician's decision about the ideal time for RTP. Level of Evidence III, Systematic review of Level III studies.

Keywords: Anterior Cruciate Ligament Reconstruction. Sports. Arthroplasty. Knee.

\section{RESUMO}

Objetivo: Revisar sistematicamente e meta-analisar o desempenho de atletas que retornaram (RTP) e não retornaram (não RTP) ao esporte em diferentes ferramentas de avaliação após cirurgia de ligamento cruzado anterior (RLCA). Métodos: De 182 estudos pesquisados no PubMed, 11 tiveram grupos RTP e não RTP avaliando a performance de jovens, praticantes de distintas modalidades esportivas, em diferentes ferramentas. Resultados: Houve melhor simetria dos membros (7,13\% [95\%/C 4,55; 9,70], $\mathrm{p}<0,0001$ ), escala de atividade de Tegner (2,41 [95\%/C 0,18; 4,64], $\mathrm{p}=0,03)$, escores funcionais como o International Knee Documentation Comittee (7,44 [95\%/C 4,69; 10,19], p < 0.001), Knee Osteoarthritis Outcome Score para qualidade de vida $(14,75$ [95\%/C 10,96; 18,54], p < 0,001) e esportes/recreação $(11,86$ [95\%/C 8,87; 14,86], $\mathrm{p}<0,001)$; e frouxidão ligamentar do joelho $(-0,25 \mathrm{~mm}$ [95\%/C -0,36; -0,14], p < 0,001) em RTP comparados com pacientes não RTP após RLCA. Conclusão: Concluímos que essas ferramentas conseguem diferenciar pacientes RTP de não RTP, o que deverá contribuir com a decisão de médicos sobre o momento ideal de retorno ao esporte. Nível de Evidência III, Revisão sistemática de Estudos de Nível III.

Citation: Andrade ALL, Sardeli AV, Livani B, Belangero WD. Determinants of return to play after anterior cruciate ligament reconstruction. Acta Ortop Bras. [online]. 2020;28(5):303-310. Available from URL: http://www.scielo.br/aob.

\section{INTRODUCTION}

Although advancements has occurred in the last years regarding anterior cruciate ligament reconstructions (ACLR), some athletes cannot return to play (RTP). There is no consensus to indicate a precise criterion to release athletes and sports practitioners to RTP after ACLR. A systematic review, showed that $40 \%$ of 264 studies failed to provide any criteria for RTP, whereas most studies apply post-operative time as the sole criteria, ${ }^{1}$ and only few studies applied criteria as muscle strength, range of motion, stability measurements, and questionnaires. ${ }^{1}$ Although some associations of these criteria with poor prognostic in ACLR patients has been shown, ${ }^{2,3}$ we are not aware of a consensus confirming whether these scores really differ in RTP and non-RTP patients. A few modifiable risk factors have been combined as a functional testing algorithm to support the decision for a rehabilitation treatment for RTP; ${ }^{4}$ however, one must consider, non-modifiable risk factors, such as age, gender or time post ACLR to RTP could determine RTP success. ${ }^{5,6}$

This systematic review and meta-analysis aims to compare Limb Symmetry Indexes (LSI), Tegner activity scale, knee laxity, and functional scores such as International Knee Documentation Committee (IKDC), Knee Osteoarthritis Outcome score for quality of life (KOOS-QOL), and Sports/Recreation (KOOS-Sports) between RTP

All authors declare no potential conflict of interest related to this article.

The study was conducted at Universidade de Campinas

Correspondence: André Luís Lugnani de Andrade. School of Medical Sciences, Rua Tessália Vieira de Camargo, 126, Cidade Universitária Zeferino Vaz, Campinas, SP, Brazil, 13083887. drandre@unicamp.br 
and non-RTP patients after ACLR. The effects between RTP and non-RTP will support the decision-making process of physicians, physical therapists, athletic trainers, and coaches about treatments and facilitate the decision of ideal time for RTP.

\section{MATERIALS AND METHODS}

\section{Study search and selection}

We conducted a systematic search on MEDLINE with the last update on November 2018. The search included "anterior cruciate ligament reconstruction" as a MeSh term and "return to sport" as MeSh term or "Return to Play" in title and abstracts. The flowchart of the study is detailed in Figure 1. We selected the studies comparing surgery success of RTP individuals and non-RTP individuals after ACLR. Six patient-oriented outcome measures were chosen due to their applicability in clinical practice as well as the prevalence of these outcomes on the studies included. Thus, we included in the systematic review studies reporting measures for at least one of the selected outcomes: LSI, Tegner activity scale, knee laxity, IKDC, KOOS-QOL and KOOS-Sports.

Studies were selected independently by two investigators. After overall screening, 11 studies were included and each RTP group within studies were treated as a separated study using non-RTP as control group for meta-analyses. Different time points of assessment were also considered different studies for meta-analyses.

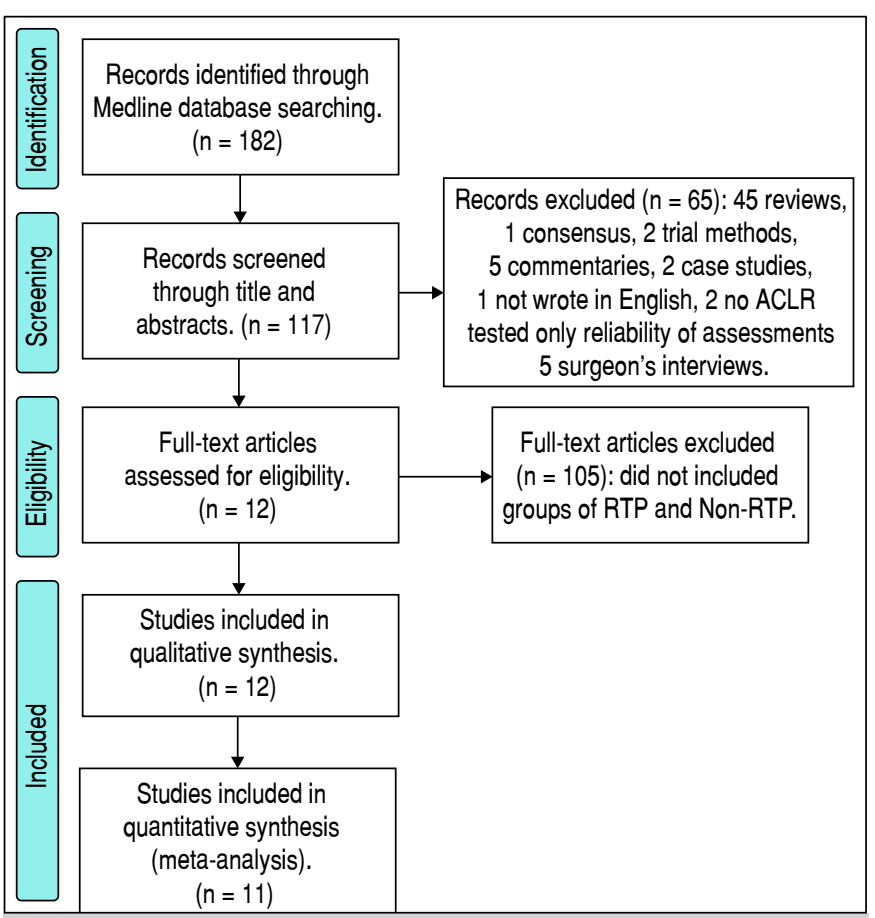

Figure 1. Flowchart of the studies selection.

Caption: ACLR: anterior cruciate ligament reconstruction; RTP: return to play; Non-RTP: non return to play.

\section{Outcomes}

LSI. Functional performance was assessed by dynamometer strength or hop tests and Limb Symmetry Indexes (LSI) was estimated based on the equation: LSI\% = [strength of involved limb/ strength of uninvolved limb] * 100 , for each participant. ${ }^{7}$ Protocols using dynamometer included isometric and isokinetic evaluation for knee extension with $60 \%$, $180 \%$ and $300 \%$ s. Hop tests included were single hop, crossover hop, square hop, triple hop, 6-m timed hop. Higher values of LSI represent better functional performance, considering the injured limb (involved) reached more similar strength than the non-injured limb (uninvolved).

Tegner activity scale. Tegner activity scale is graded between 0 (do not walk on even ground) and 10 (elite national/international soccer player), embracing different activities in daily life, as well as recreational and competitive sports. Activities resulting in score between 5 and 10 can only be achieved by recreational or competitive sport practitioners. ${ }^{8}$ Thus, the higher score for Tegner activity scale means the higher level of activity.

Knee laxity. Knee laxity is measured by an arthrometer. The arthrometer was developed to compare anterior tibial translation between non-injured knee and injured (reconstructed knee). The measures are taken from both knees and the mean displacement recorded in millimeters. The side-to-side difference is recorded as the injured knee score minus the non-injured knee score, to confirm normal knee laxity after surgery. ${ }^{9}$ Thus, higher values for knee laxity mean worst results.

IKDC. The International Knee Documentation Committee (IKDC) is a form composed of nine subjective questions evaluating Knee symptoms, function, and sports activity, regardless of a specific disease..$^{10} \mathrm{IKDC}$ has been widely used for ACLR evaluation and the higher IKDC values (scale from 0 to 100 points) the better the results. KOOS-QOL and KOOS-Sports. The Knee injury and Osteoarthritis Outcome Score (KOOS) is an extension of the WOMAC Osteoarthritis Index aimed at assessing symptoms and function in subjects with knee injury and osteoarthritis. Despite KOOS holds five separately scored subscales, in this study only those more prevalent subscales among the studies were included, the knee-related Quality of Life (QOL) and Function in Sport and Recreation (Sport/Rec). This questionnaire has been specifically validated for anterior cruciate ligament reconstruction ${ }^{11}$ and it is a valid, reliable, and responsive self-administered instrument. ${ }^{12}$ The higher KOOS values (scale from 0 to 100 points) the better the results.

\section{Data extraction}

Mean, standard deviation (SD), and sample size (n) were used for analysis. Standard error (SE) was converted into SD by the equation $S D=S E x(\sqrt{n})$, if $S D$ was not provided in the original study. Furthermore, median and interquartile range (IQR) were replaced by mean and $S D(S D=(I Q R / 1.35)) .{ }^{13}$ One of the studies presented the Knee laxity for each leg separately. ${ }^{6}$ Thus, the ratio of injured limb/ non-injured limb was estimated to obtain the same scores presented by the other studies for knee laxity. One study presented data only on box plots,${ }^{14}$ thus we extracted median and IQR from the figures using the online software WebPlotDigitizer before conversion into mean and SD. Characteristics of study populations, ACLR, and RTP were clustered for further sub-group analysis.

\section{Statistical analyses}

The six meta-analyses were performed using Comprehensive Meta-Analysis (CMA) software, version 3.3.070. The effect was estimated based on the difference between RTP and non-RTP groups or between RTP group limbs difference and non-RTP groups limbs difference for LSI. We used raw mean difference (RMD) and 95\% confidence interval for all 6 meta-analyses, considering that variables were presented by the same unit of measurements among all studies. When no statistical significance was presented for heterogeneity, fixed effect models were selected for analyses (KOOS-Sport and Knee laxity) and when statistical significance was presented for heterogeneity, randomized effect models were selected for analyses (LSI, Tegner, IKDC and KOOS-QOL). Conservative pre-post correlations of 0.5 were assumed. ${ }^{15}$ Egger's tests were performed to check the risk of publication bias in each meta-analysis. 
Sub-group analyses were planned to run for gender, age, and time to RTP for all variables. However, due to the low number of groups in each category for most variables only age (adolescents versus young patients) were analyzed for LSI and a comparison between the assessment by dynamometer and hop tests was also analyzed for LSI.

\section{RESULTS}

Table 1 shows details of the studies included. There was no risk of publication bias for Tegner activity scale, IKDC, KOOS-QOL, KOOS-Sports, and knee laxity considering $p>0.05$ for Egger tests; however, risk of bias was significant for LSI $(p=0.01)$.

LSI was measured by dynamometer (only knee extension strength assessments were included) or hop tests and the final score represents the percentage of strength of the injured limb compared to non-injured limb. Studies reporting only the mean group strength in each limb without showing the proportion of injured limb to the uninjured limb were not included in this analysis, considering there was no reliable way to estimate LSI. ${ }^{6,16}$ Figure 2 shows that LSI was higher for RTP than non-RTP $(\mathrm{RMD}=7.13 \%, \mathrm{p}<0.001)$, that is, individuals able to return to play had a mean of $7.13 \%$ higher symmetry between their injured and non-injured limbs. Regarding subgroup analysis, Table 2 shows, LSI difference between RTP and non-RTP was higher when assessed by dynamometer compared to hop tests. LSI difference between RTP and non-RTP was higher for adolescents compared to young individuals.

Table 1. Characteristics of studies included.

\begin{tabular}{|c|c|c|c|c|}
\hline $\begin{array}{l}\text { First author, year } \\
\text { (subgroup) }\end{array}$ & $\begin{array}{l}\text { Gender. Group age }(y) . \\
\text { Level of play before } \\
\text { injury. Time to RTP }\end{array}$ & Graft type & Exclusion criteria & RTP criteria \\
\hline Burland et al. ${ }^{17}$ & $\begin{array}{l}\text { Both. } 15.9 \pm 1.8 \text { (non-RTP } \\
15.6 \pm 1.9 \text { ). NR. Time to } \\
\text { RTP: } 7.4 \pm 1.9 \text { mo. }\end{array}$ & Hamstrings autograft. & $\begin{array}{l}\geq 19 y \text { of age. Failed to follow up. Had } \\
\text { a previous surgery on the contralateral } \\
\text { knee. Had reconstructive surgery } \\
\text { with a bonepatellar tendon-bone } \\
\text { graft. Underwent a revision surgery. } \\
\text { Sustained a multiligamentous injury. }\end{array}$ & $\begin{array}{l}\text { Full pain-free range of motion; resolution } \\
\text { of joint effusion; an LSI of } 80 \% \text { for } \\
\text { quadriceps isometric and isokinetic } \\
\text { testing at } 180 \% \text { s; and a satisfactory } \\
\text { score on the Noyes hop test. }\end{array}$ \\
\hline Fältström et al. ${ }^{18}$ & $\begin{array}{l}\text { Women. } 20.1 \pm 2.3 \text { (non- } \\
\text { RTP } 20.8 \pm 3.0 \text { ). Elite; } \\
\text { Sub-elite; Recreational level. } \\
\text { Time to RTP: } 6 \text { to } 36 \text { mo. }\end{array}$ & $\begin{array}{l}\text { Hamstrings; pattelar } \\
\text { tendon; others. }\end{array}$ & $\begin{array}{l}\text { Had returned to football but were } \\
\text { not currently playing. Just played } \\
\text { football at the injury occasion. Have } \\
\text { never played football. Bilateral } \\
\text { ACL injury. Re-rupture or revision } \\
\text { ACLR. Still under rehabilitation. }\end{array}$ & $\begin{array}{l}\text { Currently playing football after ACLR } \\
\text { (training with the team) and currently } \\
\text { playing at any level at the time of } \\
\text { follow-up (current players). }\end{array}$ \\
\hline Takazawa et al. ${ }^{19}$ & $\begin{array}{l}\text { Both. } 24.0 \pm 4.0 \text { (non-RTP } \\
27.1 \pm 6.7 \text { ). NR. Time to } \\
\text { RTP: } 38.2 \pm 10.2 \text { mo. }\end{array}$ & $\begin{array}{l}\text { Primary ACLR: Hamstring- } \\
\text { single bundle; Hamstring- } \\
\text { double bundle; lliotibial } \\
\text { tract; and Artificial. } \\
\text { Revision ACLR: BPTB } \\
\text { patellar tendon autografts. }\end{array}$ & $\begin{array}{l}\text { History of previous revision } \\
\text { reconstruction. Reason not otherwise } \\
\text { described, including not using } \\
\text { BTPB gratfs. High tibial osteotomy } \\
\text { was needed after surgery. Tegner } \\
\text { activity scale was less than } 4 . \\
\end{array}$ & $\begin{array}{l}\text { Full postoperative rehabilitation program } \\
\text { had been completed, and the patients } \\
\text { had achieved a full range of knee } \\
\text { motion and adequate knee stability. }\end{array}$ \\
\hline $\begin{array}{l}\text { Hamrin Senorski } \\
\text { et al. }{ }^{16} \text { (Men) }\end{array}$ & $\begin{array}{l}\text { Men. } 23.7 \pm 4.5 \text { (non- } \\
\text { RTP } 23.3 \pm 4.2 \text { ). Knee- } \\
\text { strenuous sports. Time } \\
\text { to RTP: } 10.2 \pm 3.1 \mathrm{mo} \\
\text { (non-RTP } 9.8 \pm 3.4 \mathrm{mo} \text { ). }\end{array}$ & NR & $\begin{array}{l}\text { Follow up other than 6-18 } \\
\text { months. Tegner Activity Scale } \\
<6 \text {. Still in rehabilitation. }\end{array}$ & $\begin{array}{l}\text { Patients who had returned to their pre- } \\
\text { injury level Tegner } \pm 1 \text { but a minimum } \\
\text { of Tegner } 6 \text {, and two, patients who had } \\
\text { returned to a Tegner of } 6 \text { or higher. }\end{array}$ \\
\hline $\begin{array}{l}\text { Hamrin Senorski } \\
\text { et al. } .^{16} \text { (Women) }\end{array}$ & $\begin{array}{l}\text { Women. } 20.8 \pm 3.0 \text { (non- } \\
\text { RTP } 21.4 \pm 3.8 \text { ). Knee- } \\
\text { strenuous sports. Time } \\
\text { to RTP: } 10.1 \pm 3.1 \mathrm{mo} \\
\text { ("non-RTP } 10.8 \pm 3.7 \mathrm{mo} \text { ). }\end{array}$ & NR & $\begin{array}{l}\text { Follow up other than 6-18 } \\
\text { months. Tegner Activity Scale } \\
<6 \text {. Still in rehabilitation. }\end{array}$ & $\begin{array}{l}\text { Patients who had returned to their pre- } \\
\text { injury level Tegner } \pm 1 \text { but a minimum } \\
\text { of Tegner } 6 \text {, and two, patients who had } \\
\text { returned to a Tegner of } 6 \text { or higher. }\end{array}$ \\
\hline $\begin{array}{l}\text { McCullough et al. }{ }^{20} \\
\text { (High School) }\end{array}$ & NR & Autograft, allograft. & Multi-ligament injuries. & NR \\
\hline $\begin{array}{c}\text { McCullough } \\
\text { et al. }{ }^{20} \text { (College) }\end{array}$ & NR & Autograft, allograft. & Multi-ligament injuries. & NR \\
\hline Müller et al. ${ }^{21}$ & $\begin{array}{l}\text { Both. } 31.4 \pm 10.3 \text { (non-RTP } \\
33.0 \pm 10.5 \text { ). Level I or } \\
\text { level II recreational sports. } \\
\text { Time to RTP: } 9.2 \pm 3.1 \mathrm{wk} \\
\text { ("non-RTP: } 10.8 \pm 4.1 \mathrm{wk} \text { ) }\end{array}$ & Hamstring graft. & $\begin{array}{l}\text { Concomitant injuries, such as } \\
\text { injuries involving lateral ligaments } \\
\text { or menisci, adjacent joints (hip or } \\
\text { foot) or the contralateral leg. Patients } \\
\text { with other orthopaedic, internal, } \\
\text { neurological or psychiatric diseases, } \\
\text { as well as pregnant women. }\end{array}$ & $\begin{array}{l}\text { At the 6-month surgeon's examination, the } \\
\text { operated knee joint had to be free of pain, } \\
\text { without irritation, and it had passively full } \\
\text { range of motion. The Lachman and Pivot } \\
\text { Shift Test had to be positive. The patients } \\
\text { had to be able to stand and hop on the } \\
\text { operated leg and did not report a subjective } \\
\text { feeling of instability. They had to be able to } \\
\text { perform level Ill activities without symptoms. }\end{array}$ \\
\hline $\begin{array}{l}\text { Rodríguez-Roiz, } \\
2015^{22} \text { (RTP-SL) }\end{array}$ & $\begin{array}{l}\text { Both. } 30 \text { ( } 14 \text { to } 52 \text { ). } \\
\text { Recreational sports. Time } \\
\text { to RTP: until } 36 \mathrm{mo} \text {. }\end{array}$ & Hamstring graft. & $\begin{array}{l}\text { Multiple ligament injury. Chondral } \\
\text { lesions above } 1 \text { square } \mathrm{cm} \text {. } \\
\text { History of previous surgery on } \\
\text { the same knee. ACL revision } \\
\text { surgery. Bilateral ACL injury. }\end{array}$ & NR \\
\hline
\end{tabular}


Table 1. Characteristics of studies included.

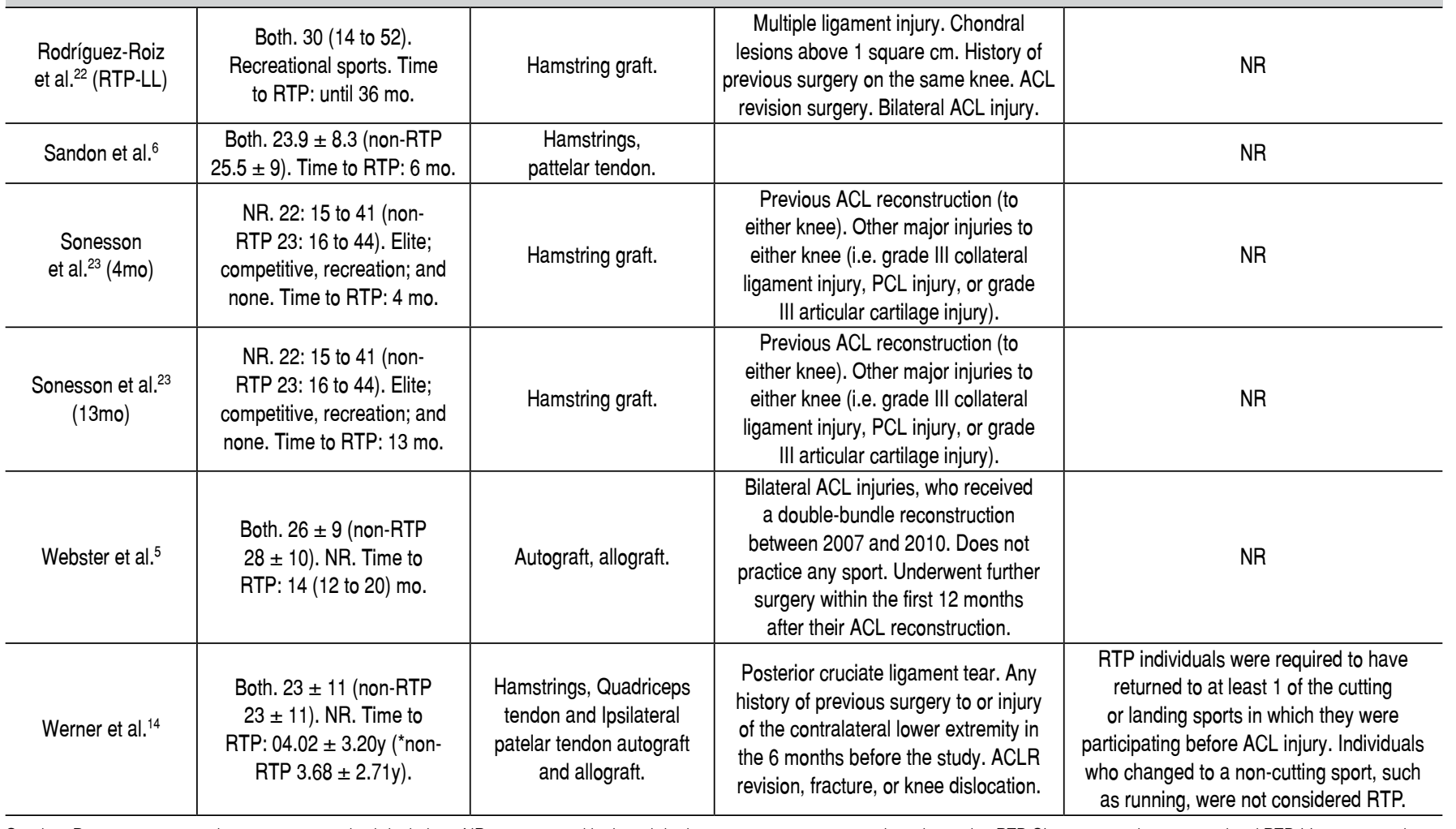

Caption: Data was presented as mean \pm standard deviation; NR: not reported in the original paper; $y$ : years; mo: months; wk: weeks; RTP-SL: return to play at same level RTP-LL: return to play at lower level; BPTB: bone-patellar-tendon-bone; ACLR: anterior cruciate ligament reconstruction; *Time to RTP for non-RTP group refers to time point assessments in this group.

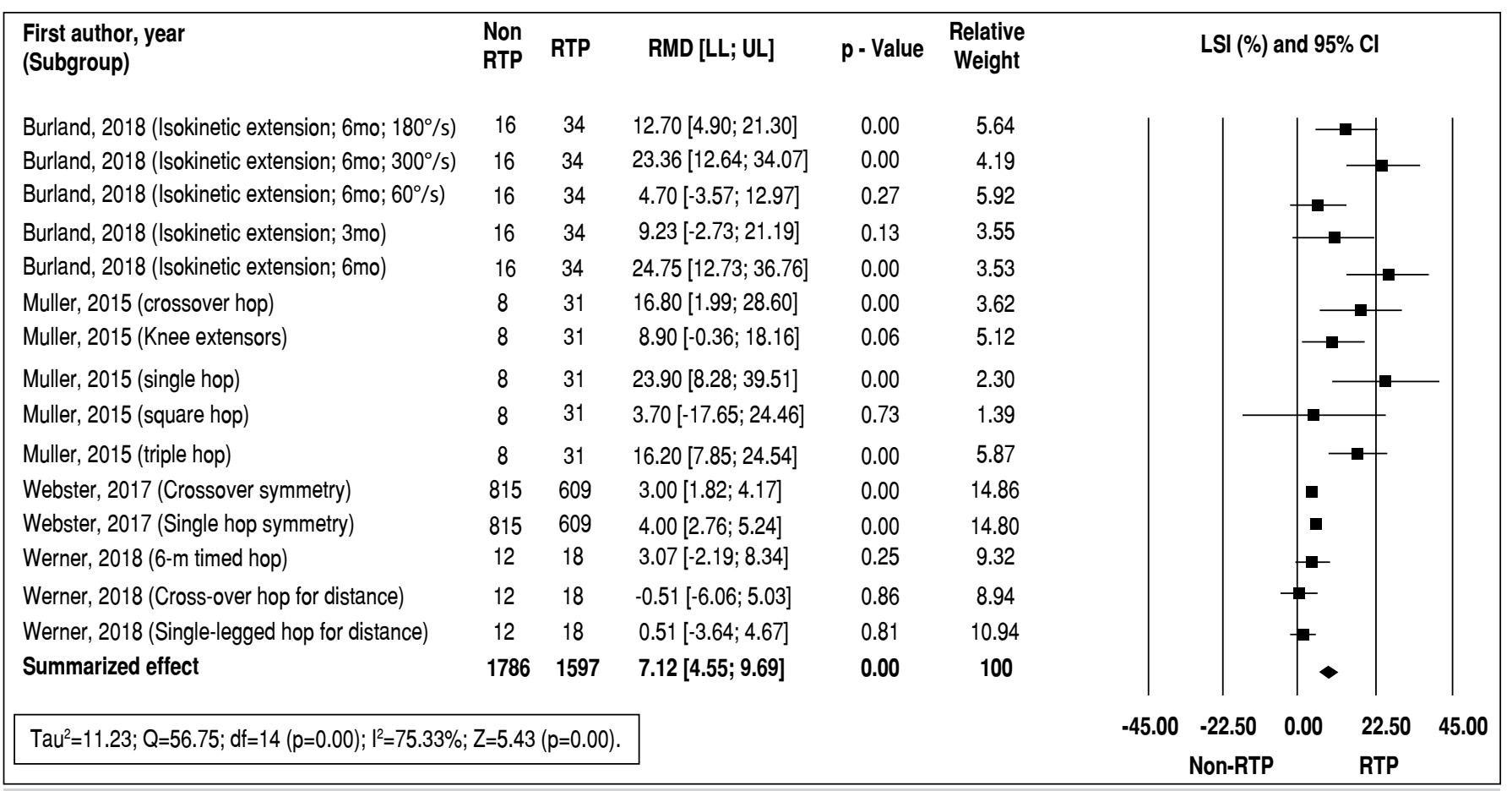

Figure 1. Flowchart of the studies selection.

Activity score assessed by Tegner was significantly higher $(\mathrm{RMD}=2.41[0.18 ; 4.64], p=0.03)$ for RTP than non-RTP (Figure 3). Regarding functional scales, RTP presented higher IKDC (RMD = 7.44 [4.69; 10.19], $p<0.001)$, KOOS-QOL (RMD = 14.75 [10.96; 18.54], $p<0.001)$ and KOOS-Sports $(\mathrm{RMD}=11.86$ [8.87; 14.86], $p<0.001)$ than non-RTP (Figures 4, 5, and 6).

Figure 7 shows knee laxity was lower in RTP (RMD $=-0.25$ [-0.36; -0.14], $p<0.001)$. 


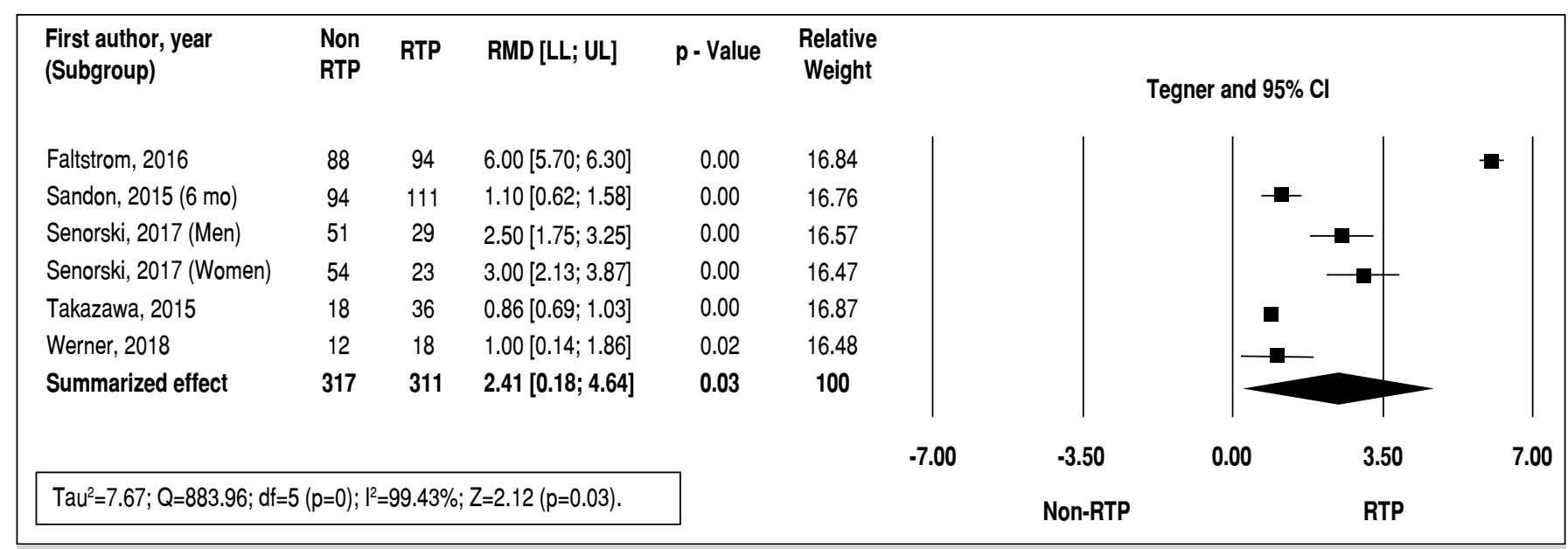

Figure 3. Forest Plot of raw mean difference (RMD) of Tegner between RTP and non-RTP.

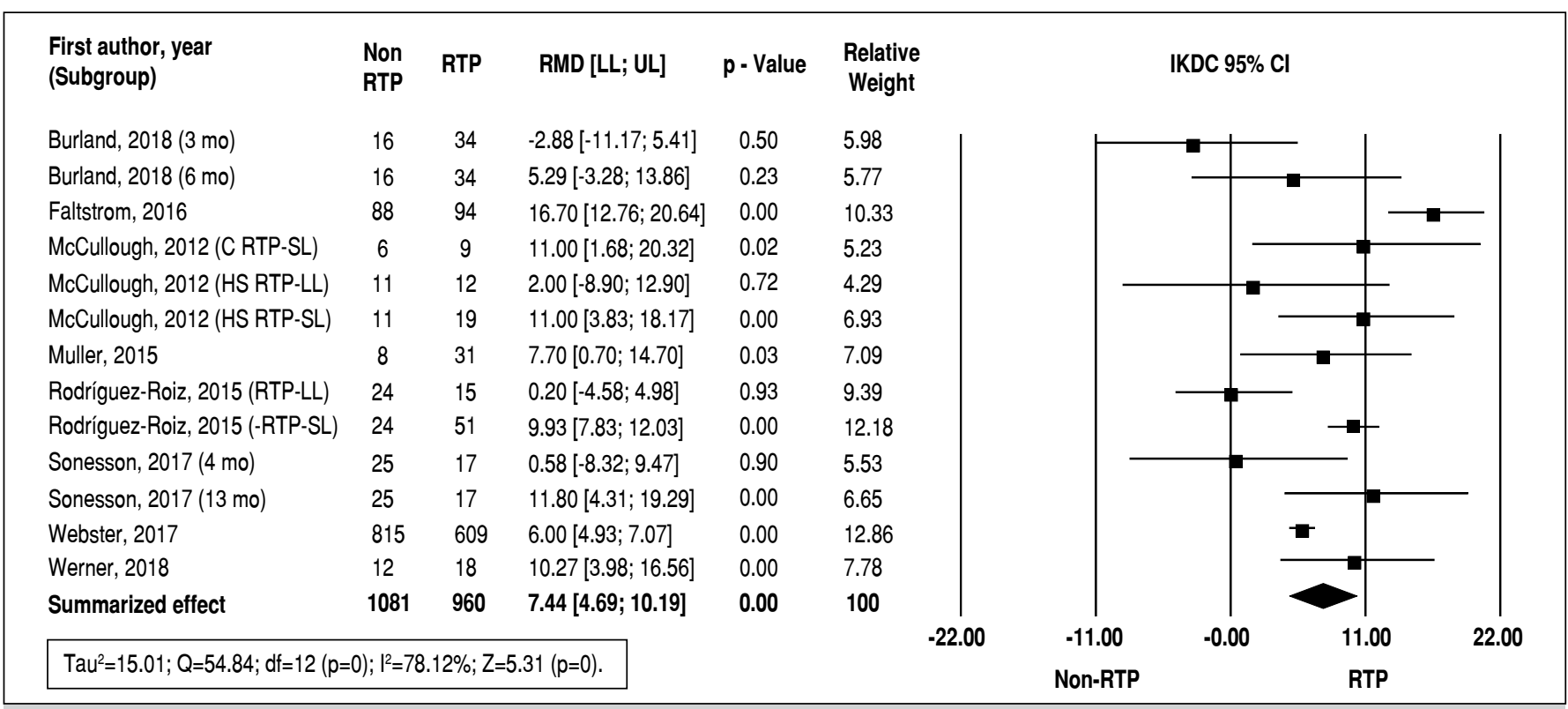

Figure 4. Forest Plot of raw mean difference (RMD) of IKDC between RTP and non-RTP.

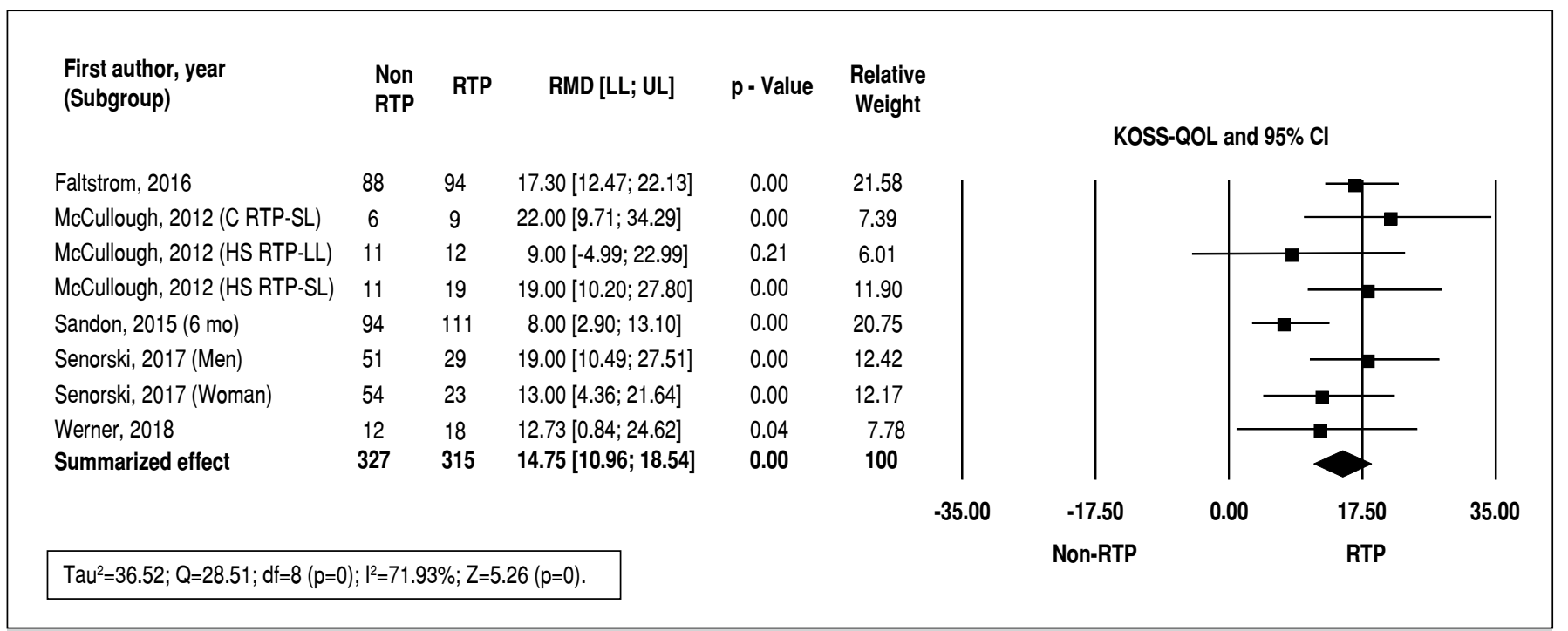

Figure 5. Forest Plot of raw mean difference (RMD) of KOOS-QOL between RTP and non- RTP. 


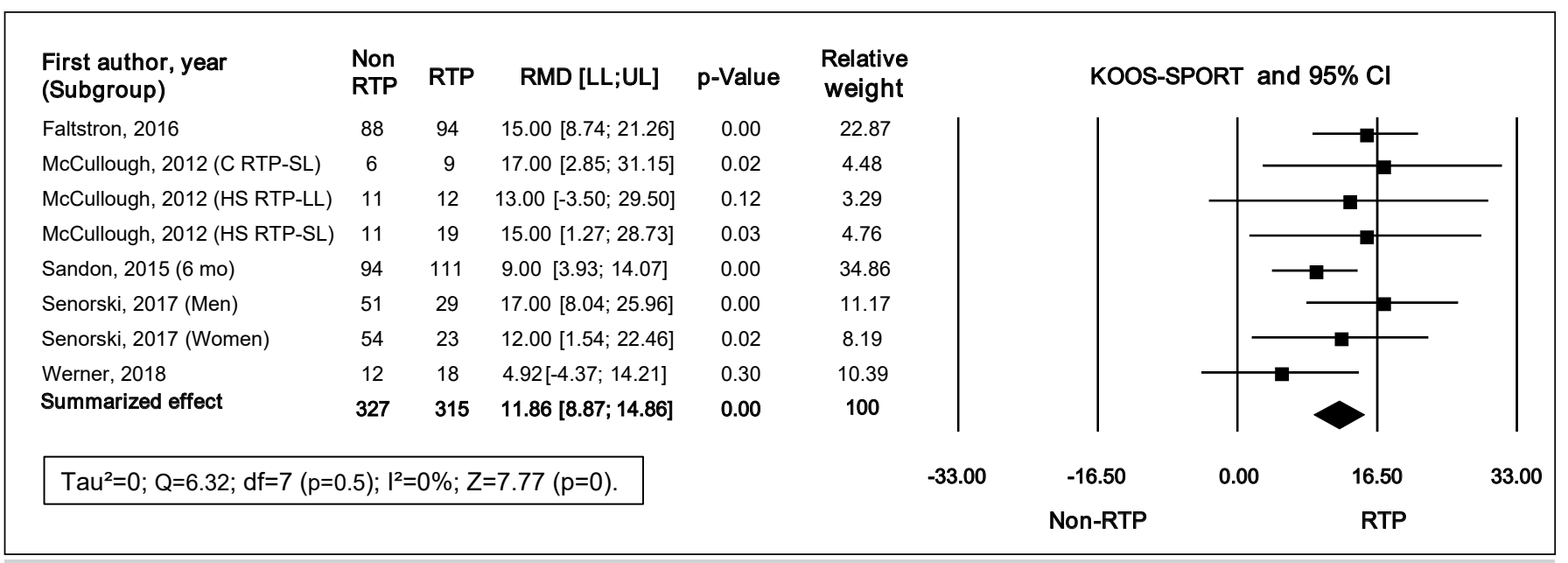

Figure 6. Forest Plot of raw mean difference (RMD) of KOOS-Sport between RTP and non- RTP.

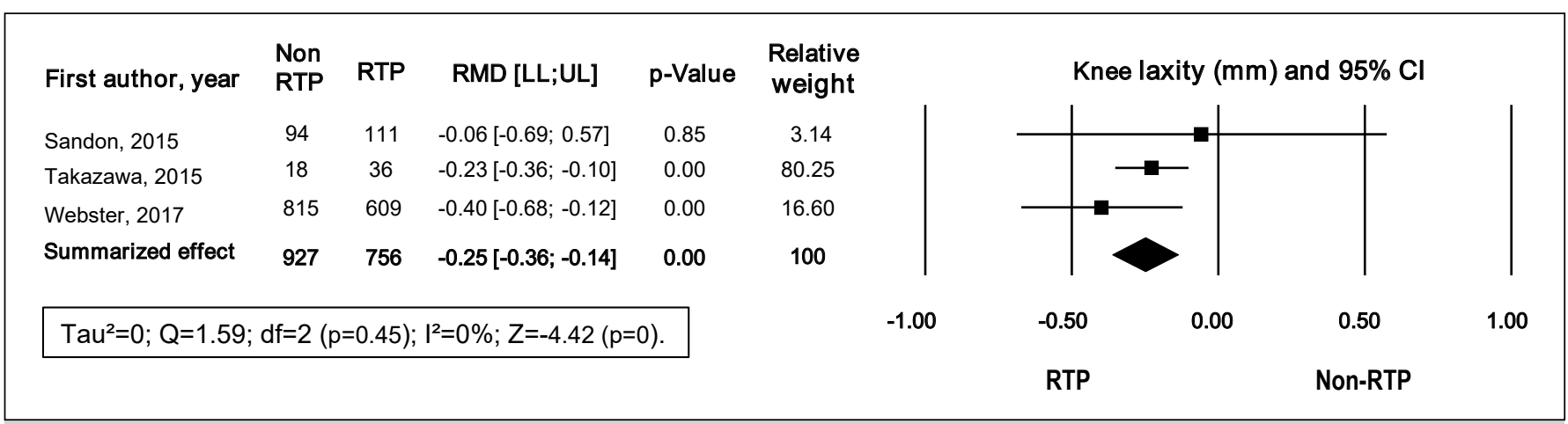

Figure 7. Forest Plot of raw mean difference (RMD) of knee laxity between RTP and non- RTP.

Table 2. Subgroup analysis of raw mean difference (RMD) of LSI between RTP and non-RTP.

\begin{tabular}{|c|c|c|c|c|c|}
\hline Test & K & References & RMD (95\%Cl) & $P$ value & $P$ difference \\
\hline Hop tests & 9 & $5,14,21$ & $4.21(3.11 ; 7.46)$ & $<0.001$ & \\
\hline Age & K & & RMD (95\%Cl) & $P$ value & $P$ difference \\
\hline Adolescents & 5 & 17 & $14.45(6.77 ; 22.12)$ & $<0.001$ & 0.014 \\
\hline
\end{tabular}

Caption: K: number of RCTs; RMD: raw mean difference; Cl: confidence interval.

\section{DISCUSSION}

In total, 11 studies assessing RTPC parameters in adolescents or young patients, athletes or recreational sports practitioners from different modalities were included. Table 1 shows characteristics such as gender, age, level of play before injury, time to RTP, graft type, exclusion criteria, and RTP criteria.

Our meta-analyses show that all RTPC parameters tested were able to differentiate RTP to non-RTP patients. LSI, Tegner activity scale, IKDC, KOOS-QOL, and KOOS-Sports were higher, whereas knee laxity was lower in RTP patients. The higher number of studies using LSI, enabled further sub-group analysis. Thus, other significant factors to be discussed in the next paragraphs were identified. LSI assessed by dynamometer better differentiate RTP from nonRTP patients compared to hop tests. Our findings combined with the risk of knee overload or injury during hop tests ${ }^{24}$ suggest, if available, the use of a dynamometer for LSI.
Regarding the effect of age, the studies included in the systematic review were homogeneous, comparing patients younger than 30 years old. Among adolescents, the LSI difference between RTP and non-RTP (RMD $=14.45[95 \% \mathrm{Cl} 6.77 ; 22.13] p<0.001)$ is even higher than young patients $(\mathrm{RMD}=4.44[95 \% \mathrm{Cl} 2.19 ; 6.70]$ $p<0.001)$. On the other hand, McCullogh et al..$^{25}$ comparing college and high school athletes did not find difference for KOOS-QOL, KOOS-Sport, and IKDC scores between RTP and non-RTP. This finding suggests that age could have higher effect for differentiate RTP and non-RTP patients when LSI is used instead of KOOS-QOL, KOOS-Sport, and IKDC. We expect younger individuals to undergo better recovery after surgery, however, it is known that younger individuals undergo higher chance of ACL revision. ${ }^{25}$

McCullough et al. ${ }^{20}$ and Rodríguez-Roiz et al. ${ }^{22}$ brought an excellent information regarding different types of RTP. For example, RTP 
patients could return to the same level they used to play or lower levels after ACLR. Thus, based on the effects of these studies in our analyses, we noticed only RTP patients returned to the same levels, showing significantly higher IKDC, KOOS-QOL, and KOOSSports than non-RTP patients (Figures 4, 5, and 6), whereas RTP patients returning to lower levels did not differ from non-RTP in these RTPC parameters.

Regarding gender comparisons only three studies had their samples exclusively composed of men or women, whereas the others presented mixed gender samples, precluding sub-group analysis for this variable. Nevertheless, Hamrin Senorski et al. ${ }^{16}$ compared men and women in their study. They found higher Tegner activity scale, KOOS-QOL, and KOOS-Sports scores for RTP than non-RTP for both men and women groups.

Time after ACLR might influence RTP. Among patients returning to play 9 months after ACLR, higher LSI occurred simultaneously with reduced knee injury rate. ${ }^{3}$ Burland et al. ${ }^{17}$ directly tested the difference on RTPC between RTP and non-RTP 3 and 6 months after ACLR. They analyzed athletes from different modalities, and they found IKDC and LSI were not different between RTP and non-RTP at 3 months, however LSI became higher in RTP than non-RTP after 6 months. Although IKDC seems to be higher after 6 months, it was also higher in non-RTP patients, leading to similar values between RTP and non-RTP also at 6 months.

Although we did not include psychological factors that might influence RTP in the present meta-analyses, Sonesson et al., ${ }^{23}$ assessing athletes from different sports modalities, found RTP patients were more motivated during rehabilitation to chase their pre-injury level and were more satisfied with their activity level and knee function one year after ACLR. Fältström et al. ${ }^{18}$ also found higher motivation in RTP female soccer players. Despite the higher chance of RTP for athletes undergoing ACLR sooner after injury, RTP soccer players also presented significant higher ratings for psychological readiness to return to sport. Nevertheless, the benefits of psychological factors over RTP in both studies aforementioned happened simultaneously with other functional improvements that might affect RTP as well, precluding the isolated understanding of psychological factors influence on RTP.

Note that most evaluations analyzed herein are commonly used by physicians in clinical practice as part of the criteria to release patients to play and they could be a cause of the differences we found between RTP and non-RTP. However, as we showed in Table 1 , they were not consistent among studies and many protocols of release to RTP were not described. The expected higher values for Tegner Activity in RTP could be a confounding factor, considering that patients returning to play could reach higher scores. Still, this study shows the difference between RTP and non-RTP for most used RTPC

The significant risk of publication bias for LSI is a limitation of the literature. Studies identifying higher LSI for RTP than non-RTP might be more likely to be published in indexed journals or it could just be a coincidence, considering LSI was the parameter commonly used by the included papers.

\section{CONCLUSION}

In fact, after pooled analyses the selected RTPC parameters were determinant to differentiate RTP for non-RTP patients. Our findings support that therapies following ACLR might target higher LSI, Tegner activity scale, IKDC, KOOS-QOL, KOOS-Sport and lower knee laxity to reach the same level RTP in patients on different modalities. Moreover, LSI assessed by dynamometer performed better than hop test to differentiate RTP from non-RTP. Furthermore, the narrow age range of young patients of the studies included in our systematic review limits the applicability of our findings to older patients.

AUTHORS' CONTRIBUTIONS: Each author contributed individually and significantly to the development of this article. ALLA: development of the research project, writing, and review; AVS: writing and statistical analysis; BL: overall concept of the study and review; WDB: overall intellectual concept of the study and review.

\section{REFERENCES}

1. Barber-Westin SD, Noyes FR. Factors used to determine return to unrestricted sports activities after anterior cruciate ligament reconstruction. Arthroscopy. 2011;27(12): 1697-705

2. Della Villa F, Ricci M, Perdisa F, Filardo G, Gamberini J, Caminati D, et al. Anterior cruciate ligament reconstruction and rehabilitation: predictors of functional outcome. Joints. 2015;3(4):179-85

3. Grindem H, Snyder-Mackler L, Moksnes H, Engebretsen L, Risberg MA. Simple decision rules reduce reinjury risk after anterior cruciate ligament reconstruction: the Delaware-Oslo ACL cohort study. Br J Sports Med. 2016;50(13):804-8.

4. Davies GJ, McCarty E, Provencher M, Manske RC. ACL return to sport guidelines and criteria. Curr Rev Musculoskelet Med. 2017;10(3):307-14.

5. Webster KE, Feller JA. Younger patients and men achieve higher outcome scores than older patients and women after anterior cruciate ligament reconstruction. Clin Orthop Relat Res. 2017;475(10):2472-80.

6. Sandon A, Werner S, Forssblad M. Factors associated with returning to football after anterior cruciate ligament reconstruction. Knee Surg Sports Traumatol Arthrosc. 2015;23(9):2514-21.

7. Noyes FR, Barber SD, Mangine RE. Abnormal lower limb symmetry determined by function hop tests after anterior cruciate ligament rupture. Am J Sports Med. 1991;19(5):513-8

8. Tegner Y, Lysholm J. Rating systems in the evaluation of knee ligament injuries. Clin Orthop Relat Res. 1985;(198):43-9.

9. Malcom LL, Daniel DM, Stone ML, Sachs R. The measurement of anterior knee laxity after ACL reconstructive surgery. Clin Orthop Relat Res. 1985;(196):35-41.

10. Irrgang JJ, Anderson AF. Development and validation of health-related quality of life measures for the knee. Clin Orthop Relat Res. 2002;(402):95-109.
11. Roos EM, Roos HP, Lohmander LS, Ekdahl C, Beynnon BD. Knee Injury and Osteoarthritis Outcome Score (KOOS) - development of a self-administered outcome measure. J Orthop Sports Phys Ther. 1998;28(2):88-96.

12. Roos EM, Lohmander LS. The Knee injury and Osteoarthritis Outcome Score (KOOS): from joint injury to osteoarthritis. Health Qual Life Outcomes. 2003;1:64.

13. Hozo SP, Djulbegovic B, Hozo I. Estimating the mean and variance from the median, range, and the size of a sample. BMC Med Res Methodol. 2005;5:13.

14. Werner JL, Burland JP, Mattacola CG, Toonstra J, English RA, Howard JS. Decision to return to sport participation after Anterior Cruciate Ligament Reconstruction, Part II: self-reported and functional performance outcomes. J Athl Train. 2018;53(5):464-74.

15. Borenstein M, Hedges LV, Higgins JPT, Rothstein HR. Introduction to meta-analysis. Hoboken: John Wiley \& Sons; 2009

16. Hamrin Senorski E, Samuelsson K, Thomeé C, Beischer S, Karlsson J, Thomeé R. Return to knee-strenuous sport after anterior cruciate ligament reconstruction: a report from a rehabilitation outcome registry of patient characteristics. Knee Surg Sports Traumatol Arthrosc. 2017;25(5):1364-74.

17. Burland JP, Kostyun RO, Kostyun KJ, Solomito M, Nissen C, Milewski MD. Clinical outcome measures and return-to-sport timing in adolescent athletes after anterior cruciate ligament reconstruction. J Athl Train. 2018;53(5):442-51.

18. Fältström A, Hägglund M, Kvist J. Factors associated with playing football after anterior cruciate ligament reconstruction in female football players. Scand J Med Sci Sport. 2016;26(11):1343-52.

19. Takazawa $Y$, Ikeda H, Saita $Y$, Ishijima M, Nagayama M, Kaneko H, et al. Case series: revision anterior cruciate ligament reconstructions using patellar tendon autografts. Knee. 2015;22(6):569-73. 
20. McCullough KA, Phelps KD, Spindler KP, Matava MJ, Dunn WR, Parker RD et al. Return to high school- and college-level football after anterior cruciate ligament reconstruction: a Multicenter Orthopaedic Outcomes Network (MOON) cohort study. Am J Sports Med. 2012;40(11):2523-9.

21. Müller U, Krüger-Franke M, Schmidt M, Rosemeyer B. Predictive parameters for return to pre-injury level of sport 6 months following anterior cruciate ligament reconstruction surgery. Knee Surg Sports Traumatol Arthrosc. 2015;23(12):3623-31.

22. Rodríguez-Roiz JM, Caballero M, Ares O, Sastre S, Lozano L, Popescu D. Return to recreational sports activity after anterior cruciate ligament reconstruction: a one- to six-year follow-up study. Arch Orthop Trauma Surg. 2015;135(8):1117-22.

23. Sonesson S, Kvist J, Ardern C, Österberg A, Silbernagel KG. Psychological factors are important to return to pre-injury sport activity after anterior cruciate ligament reconstruction: expect and motivate to satisfy. Knee Surg Sports Traumatol Arthrosc. 2017;25(5):1375-84.

24. Welling W, Benjaminse A, Seil R, Lemmink K, Gokeler A. Altered movement during single leg hop test after ACL reconstruction: implications to incorporate 2-D video movement analysis for hop tests. Knee Surg Sports Traumatol Arthrosc. 2018;26(10):3012-9.

25. Snaebjörnsson T, Svantesson E, Sundemo D, Westin O, Sansone M, Engebretsen $\mathrm{L}$, et al. Young age and high BMI are predictors of early revision surgery after primary anterior cruciate ligament reconstruction: a cohort study from the Swedish and Norwegian knee ligament registries based on 30,747 patients. Knee Surg Sports Traumatol Arthrosc. 2019;27(11):3583-91. 